\title{
Fashion Media Communication in Hong Kong
}

\begin{abstract}
Though fashion is a significant global creative industry it is still often regarded as wasteful and deceptive. Participant observation at a Hong Kong fashion magazine was used to remap the relationships among the conflicting notions of fashion, attempting to determine which fashion theories best describe the contemporary fashion industry in Hong Kong. This paper discusses how Hong Kong’s fashion media present luxury brands as fashionable and how editors, copywriters, designers, sales managers and photographers adapt those meanings. The observations are interpreted in terms of two schools of fashion theory and the exploitative and creative aspects of postmodern fashion are discussed.
\end{abstract}

Key words: fashion theory, fashion media, Hong Kong, China, participant observation

\section{Background}

With telegrams giving way to radio, cinema, television and now the global internet, the way fashion is marketed has been evolving toward complexity. Today, diverse online and offline media supply an endless flow of fashion messages daily. More and more images and text linked with the idea of fashion are being received and seen, if not 
fully processed. Fashion marketers create and recycle a vast array of cultural signs and symbols in their advertising and branding. Abstract and ambiguous meanings are often encoded in the text and visuals of fashion communications, often making them difficult to analyze and interpret systematically. Perceived meanings vary as the messages interact with the specific social, historical, economic and cultural situations. While the significance of these transformations deserves further scholarly exploration, the research objective is to explain how fashion media manage to generate an exclusive sense of fashion in the local context.

Although fashion is by any measure a significant, global creative industry, it is still often regarded as wasteful, deceptive or even debauched. The research reported here was an empirical study designed to illuminate which fashion theories are applied in Hong Kong's fashion industry and the hidden mechanisms involved. The research did not aim at elucidating a model of universal validity, but it attempted to represent a model potentially applicable to similar social settings, especially across the Asia-Pacific region. It investigated the role of the print media in reporting local and worldwide fashion news in Hong Kong addressing particularly how the media present brands as fashionable—-how brand managers, photographers, editors, copywriters and even advertising sales managers improvise, adapt and negotiate the meanings of fashion being presented to the public. 
This was accomplished through participant observation, interviews and case studies. Through the experience in developing an editorial feature entitled "The Fashion Marketer: Outside and Inside” at High Fashion during Summer 2011, the participant observer first conducted sixteen interviews with Asian fashion marketers. Second, through the three-month participant observation at High Fashion, the researcher also met and subsequently interviewed eight of its staff coming from all four of the magazine’s major teams—editorial, copywriting/project, design, and advertising sales. Lastly, through the social network of the fashion insiders at High Fashion, the researcher adopted snowball sampling method and got connected with and interviewed sixteen experienced and undisclosed fashion media personnel and fashion bloggers in both Hong Kong and mainland China. A coding chart was developed to code the observations and interview responses thematically, forming clusters which formed the basis of the analysis (see Appendix 1). The coded data were then applied to test selected theories and demonstrate the complexity of Hong Kong’s fashion culture(s) in relation to the West. The results demonstrate the simultaneously constraining and enabling nature of fashion. Is fashion commercial or creative? Preset or negotiable? The answers resonate with the two opposing schools of fashion theory describing it as exploitative or creative.

\section{Theorizing Fashion: To Play or Obey?}

The meaning of fashion varies in different contexts. Some define it based on its physical manifestations_-garments, shoes, accessories, cosmetics, jewelry, fragrances - but others comprehend it from a psychological, cognitive or semantic 
perspective, viewing fashion as an attitude, a signifier of newness and modernity, in some cases almost as a religion. When fashion is associated with the body, it speaks of one's facial features and shape, hues of skin, a particular silhouette and proportion of torso, styles and colors of hair and so forth. When fashion meets architectural and interior design, decor, lighting, musical arrangement and video projection come into play, signaling contemporary, trendy art somewhere between art per se and consumption. Ways of speaking, posture, walking, dancing and performing can similarly express a sense of fashion.

There are two broad camps debating views about fashion. In the Critical camp, Marx (1967), Veblen (2012), Adorno (1975), Baudrillard (2007), Barthes (1990), Derrida (1976) and Bourdieu (1993) are among those who criticize fashion as a means of economic exploitation, illogical and empty. They believed that the industry actively manipulates fashion trends to fleece the public. Veblen and Bourdieu treated fashion as a conspicuous vanity of the leisure class and a weapon in social position-taking. Both highlighted how fashion exclusively privileges the bourgeois over what in their day was termed the working classes. In contrast, Fiske (1990), Wilson (1985), Jobling (1999), Barnard (1996), Hall (2012), Lipovetsky (1994), Evans (2003) and Skov (2012) have more recently tried to go beyond the Marxist perspective, all proposing that fashion has social utility and involves multiple twists in its meanings throughout its complicated 
encoding and decoding processes. Fiske, Wilson and Lipovetsky assert that the fashion consumer/wearer too can alter fashion's meanings. Barthes and Jobling have highlighted the fashion media as fashion's mediator, generating its meanings. Evans and Skov emphasize the major role of fashion's creators and producers in encoding fashionability. In Hall's and Barnard's view, the creator, the mediator and the wearer are all involved in negotiating fashion's meanings. This study set out to test the validity of these ideas in a real social setting.

\section{Methodology}

Participant observation was the basic methodology adopted in this research. First practiced by anthropologist Frank Hamilton Cushing in 1879, participant observation involves a researcher taking part in the daily activities, rituals, interactions, and events of a group of people as a means of understanding the group's culture. It is an umbrella term for all of the observation and formal and informal interviewing in which anthropologists engage, and the usual approach in the fieldwork phase of ethnographic research (DeWalt \& DeWalt, 2002). Resting on the tripod of participation, observation and interrogation, participant observation offers three advantages: it generates good quality data from fieldwork, the exposure as a participant improves the quality of the data's interpretation, and it encourages the formulation of new research questions and 
hypotheses grounded in on-the-scene observation.

The investigator's first task is to gain entry to a field site, followed by building rapport and gaining acceptance by the community. This allows him to better interact with the groups and individuals in hopes of collecting beneath-the-surface data. Time must be invested to excel in the use of appropriate language and industry jargon to facilitate taking part appropriately in the insiders’ daily activities (DeWalt \& DeWalt, 2002). Learning what to observe and how best to observe it are also important. The process of enculturation allows the accumulation of observations of daily routines, specific events, and conversations, all of which must be carefully observed and captured accurately in field notes. The notes describe what the observer did and saw, but also details of the context, gradually allowing an understanding of people's daily lives, the structure of events, the social structure, and expectations and values which is as complete, accurate and dispassionate as possible. Properly done, such observation normally leads to well-defined, specific and relevant research questions.

In this study, participant observation was applied to a Hong Kong fashion magazine, High Fashion. Founded in 2006, High Fashion focuses on discussing high-end fashion, beauty, food, travel and entertainment. It appears at the end of every month. It is published by High Fashion Limited which also circulates Popular Fashion, 
a weekly magazine which targets younger readers and has discussed street fashion in Hong Kong since 2001. The weekly is extremely popular among teenagers in Hong Kong with a circulation of 100,000 copies per week (according to 2011 Hong Kong Population Census, there are in total 372,878 Chinese citizens aged 10 - 19 living in the city out of the total 7,071,576 citizens in Hong Kong). High Fashion emerged from Popular Fashion as its original young readers became more conscious of world fashion and lifestyles over time. High Fashion was launched to satisfy their evolved "needs". According to the publication's media sales kit, High Fashion publishes 3 different editions in Hong Kong, Taiwan and mainland China with respective circulations of 50,000, 20,000 and 300,000 copies. It has successfully attracted a group of loyal readers, many of whom describe themselves as administrative executives (27\%), artists or designers (20\%) and other professionals (31\%). 57\% are female, but $43 \%$ are male. $75 \%$ of them claim to be between 25 and 39 and about $80 \%$ claim to have a monthly income in excess of HK\$20,000 (nominally US\$2,550, but no tax is withheld on Hong Kong salaries).

This study focused on observing the staff of High Fashion. Three months of participant observation was arranged with the help of the publication's fashion editor, with whom the researcher was personally acquainted. The editorial work was observed in detail by attending editorial meetings and daily activities such as photo shoots and 
press events. The researcher contributed to writing one editorial feature during the study period. The level and duration of the participation were considered sufficient to elucidate how the magazine's personnel collaborate, dispute and negotiate. The observations were recorded in written notes. Photos were also recorded where it was acceptable and appropriate. Data reduction involved complete rereading and extensive rewriting during the observation period and afterward. The field notes were arranged chronologically, especially those documenting conversations and discussions on specific occasions.

Through the three-month period of participant observation the researcher met and interacted with staff from all four of the magazine’s major teams—editorial, copywriting/project, design, and advertising sales. The data were coded thematically to demonstrate the staff's insights into the fashion media and the industry in Hong Kong and Asia and how they go about negotiating and then encoding fashionability in their work. (The staff have been given false names and their personal traits have been altered and displaced in this report.)

In Fashion as Communication, Malcolm Barnard (1996) asserts that the designers, wearers and observers of fashion items can never be the only genuine senders of fashion messages. Fashion marketers and the fashion gatekeepers of the media also play a crucial role. There is always discrepancy between the encoded and decoded 
meanings of a fashion item, as the perceptions are the result of a constantly shifting negotiation influenced by cultural differences related to the sender's and the receiver's social and organizational status, class, gender, ethnicity and so forth. Indeed, the negotiation itself is one aspect of the cultural/social community (Barnard, 1996). Barnard's ideas are useful for examining to what extent and how fashion meanings shift and are negotiated through the communication process. This study investigated the complex interplay between fashion branding and shifting trends using real cases of collaboration between fashion marketers and the media.

A key research question was whether fashion is, as Marxist theorists suggest, purely an arbitrary, preemptive message controlled and imposed according to the preferences of fashion producers; or whether, as Barnard and other pluralist theorists assert, especially Barnard, fashionability is negotiated through the process of fashion communication. High Fashion and its personnel were observed trying to create and maintain a specific set of fashion meanings in their daily work. This involved the magazine in various forms of appropriation and negotiation in the process of encoding fashionability. The observation and interview data were juxtaposed and synchronized in an attempt to construct a clear picture of the multiple communication processes going on in and beyond the organization. 


\section{Observations at High Fashion}

The magazine relies on a triangular team structure for content creation:

copywriting, editorial and design. The copywriting team is responsible for handling advertorial, special creative and other integrated marketing projects, from taking the briefs, through coming up with creative strategies, to executing the tasks. The design team is mainly responsible for laying out the text, photos and graphics on the pages in a stylish manner. The photographers on the design team do the photography, indoors and outdoors, from product samples to fashion shows.

The chief editor — the head of the editorial team — was observed to be the most powerful figure, and the staff agreed that the editorial team superseded the others in overall decision-making. Many staff believed that artistic direction of the magazine was his strength. All the design team members (Jet, Mag and Cammy) admitted that they highly trust the chief editor Cello's aesthetic sense, and that in many previous cases his creative suggestions had led to better solutions and more artistic presentation. The various editors and reporters tended to report to Cello directly and work in an individual, isolated mode most of the time. Except in the monthly topic meetings, they did not often discuss ideas with each other. The copywriting team is the next most influential, followed by the advertising sales team, though either may override the other on certain occasions. The design team was universally seen as the second least powerful, 
outranking only the relatively passive and least powerful photographers. The in-house photographers basically take orders from everyone else.

During the interviews, many of the junior staff and even the advertising sales manager described how working at High Fashion had inspired them with a new conception of what high fashion means, as none were personally familiar with fashion prior to joining the company. Junior designer Cammy confessed. “In most cases I can’t even detect a wrongly spelt brand name in the layout. I guess I need to spend more time to get myself familiar with fashion knowledge...Spoon-feed myself like I did in high school”. Billy the advertising sales manager also explained, “After I joined High Fashion, I realized that fashion is also about mix and match and many more [factors]...Here I'm constantly absorbing new knowledge”. High Fashion staff were gradually socialized in the workplace to be interested in learning diverse aspects of fashion.

Both (Chinese) language skills and an understanding of visual communication were strongly emphasized when assessing an editorial candidate’s potential. As Kim and Kris (female fashion reporters) revealed, the latter was considered the more important—comprising not only the skills of, but also a sense of, layout design, fashion selection and styling. Those traits would be combined with an ability to work with stylists, make-up artists, photographers, graphic designers and illustrators.

Figure 1 summarizes the vigorous negotiations observed daily among High 
Fashion's staff and with various external parties.

The Copywriting and Projects Team

Creative ideas for special projects usually came from collaboration involving the client, advertising salesmen, the graphic designers and the chief editor. In many cases, the ideas were initiated and proposed by Cello. Senior copywriter Ginny, however, thought that advertising sales personnel only focused on the sales perspective but were unaware of the readers' interests. They neglected the needs of readers and advocated hard-selling product shots and texts. As the copywriting team was closely connected with the advertising sales team, all she could do was to tactfully convince the ad sales team and strike a balance between the demands of the clients and her perception of the readers' interests.

In the eyes of the journalists and designers, the copywriters worked for two masters simultaneously: advertising sales and the readers. They often had difficulty deciding which to follow and which way to go artistically. When copywriter Timothy was asked if he considered himself a fashion creator, he responded, “...it is not my role. Fashion editors are endowed with the right to choose whatever fashion items they prefer to introduce...It would be difficult in my position [to do so], we don't have such power. In the end I still take the needs of our client as my first priority.... Perhaps at the beginning of my copy I don't have to endorse the advertised product right away, maybe 
discussing this season's trend first before getting into the core message...but still very little [power].” When it comes to any disagreement between the client and the magazine regarding the direction of an advertorial or custom project, the advertising sales director would jump in to negotiate, though in many circumstances everyone had to adapt to the client's direction and suggestions.

At one point the local marketer of a well-known French fashion brand complained about the photos for a tailored cover — considered the most important type of custom project. The client felt that in all the photo options submitted for the cover, the Chinese female model looked younger than intended. He felt that did not go along with the brand's elegant and sumptuous personality, and that the brand's target customers, affluent and more mature women, would not find such a young model appealing or identify with her. Even after Timothy had gently reminded the client that the magazine's absolute deadline for bulk printing would be four days later, the client still requested that the magazine redo the photography using another, slightly older model. When sales director Shandy learned about this she appeared frustrated and puzzled, saying, "They approved that model in the first place! At this point how could we possibly re-do the photoshoot again?” Shandy immediately urged Timothy to print out all the available photos captured in the photo session so they could quickly examine them and see if there were other better options for the client's re-selection. Finally, they 
convinced the client to replace the original cover photo with another, retouched one in which the same model appeared to be more mature due to a different photographic angle, greater contrast in the lighting and a darkened tone making her eyebrows appear darker and her makeup heavier.

During the formal interviews, Timothy admitted that after two years with the magazine he understood that in fact many items introduced by fashion magazines are not genuinely the editors' choices and recommendations. More often, the "editorial content” is actually advertorials and sponsored features, and there is little genuine fashion judgment involved in creating the editorial content. Timothy had also discerned that fashion reporters tend to feature their favorite clients. Such biased editorial content might then be used by the advertising sales team as a reference or included in a media sales kit tailored for the client for the sake of selling advertising. "In the end it's about increasing ad sales. Thus I personally think that [fashion] magazines are not neutral when portraying the fashion trends...All about money. Every magazine must differ from the others somehow...Maybe other media companies are not like that, or [maybe] similar.”

The Design Team

Reporter Kim described the graphic design team as usually the passive party in fashion encoding. The graphic designers applied their aesthetic judgment and 
recommended graphical adjustments, but they still mainly followed the editorial team’s layout brief. The editorial staff usually insisted on using their original layout if it had been endorsed by the chief editor. In the process of negotiation, the designers seemed to care more about the complexity of the typesetting work and deadlines. When graphic designer Mag was asked if she saw herself as a creator of fashion, she distinctly described herself as a "passive creator”. "[At High Fashion] the idea of 'creating fashion' is all about following what Cello wants to create, not any of us....When I actually did create something on my own, Cello did not buy it...so is it still a kind of creation?” Junior designer Cammy supposed that even if media workers were to insist on their viewpoints, they would have to give in eventually. "We cannot hold to our standpoints; [the clients] always override us...We cannot hold our own till the end...What we can say is, 'Alright, whatever they want we will follow.' That's the way things are.” She described collaborating with an American outdoor wear brand. "I tried to propose several graphical ideas to them. Eventually they rejected them all and even asked 'Why don’t you just follow our [in-house] designer’s layout?’” Cammy admitted the client had provided a sample layout to the design team, but she never realized that the magazine had to replicate it faithfully. She recounted the client’s criticism, "Our designer worked so hard to create the layout. Why don't you just follow?” She did not 
understand why the marketers did not place a print advertisement right away instead of initiating the collaboration with the custom project team if the in-house designer had already fixed everything. “I don’t have a say anyway, they pay the bill and get what they want...We [the design team] had a meeting with Cello, and his comment was that it's simply a waste of time so we should just give in...See, you can never, ever express your creative ideas, because they [the client] have already got one.” When asked if there was space for negotiation, Cammy said that it was non-negotiable. “Our design team is certainly submissive... [We can't even] contact the client directly, the advertising sales team does... When we told [the ad sales team] we really didn't like the proposed styling and graphic design as it really doesn't match High Fashion's aesthetic style, they promised they would pass the message to the client, but they never did.” Cammy said she was invariably disappointed when she received responses from the client to the design team’s suggestions.

\section{The Editorial Team}

It was clear that the chief editor took a dominant role in determining the magazine’s direction, monitoring every employee's work schedule and pushing them to meet editorial deadlines and advertising sales targets. He was at once the chief editor, chief designer and head of advertising sales. Except for the fashion editor Fei Fei, most 
High Fashion staff admired Cello's ability and expressed their strong faith in his judgment.

Fei Fei exposed her discontent when Cello warned the editorial staff to be cautious about promising fashion marketers any specific amount of free editorial coverage. The number of pages allowed for editorials was tightened. Fei Fei insisted, however, that it is vital for a fashion magazine to contain an appropriate amount of non-advertorial content featuring a wide variety of fashion brands. "[I]t helps building relationships with fashion brands for potential collaboration and advertising sales in the future," she said. During a formal interview she exclaimed, "The truth is, you want to do a better job but have no resources. [In Hong Kong] there won’t be any editorial project having one or two hundred thousand [HK] dollars as a photography budget... The only way out is to do the fashion photography abroad [where free-of-charge mise-en-scènes are everywhere], but then new restrictions arise when you realize that the work is sponsored by specific fashion brands... Sometimes even after I have spent a lot of effort on it, you can’t guarantee it can be published. It happens.”

Cello elucidated the practical difficulties of featuring an "inside story" about a fashion brand. Cello, supposedly the most powerful figure at the magazine, repeatedly reminded the observer how easily the editorial team might trespass on the untouchable territory of the fashion brands. No matter how good the client's local marketing and 
communication team or fashion design team, each is only a tiny little gear in the giant fashion industry, rarely authorized to speak on behalf of the brand or about its creative direction. "They're in many cases not the creator but the messenger of fashion.” Everything has to be controlled, calculated and monitored carefully because a few incorrect messages may deviate from and thus undermine or even ruin the consistently communicated brand identity. In Cello's view, uncertain individual opinions should be suppressed, silenced and eradicated in most cases, including personal fashion tastes and favorite brands.

So who, then, could speak for a fashion brand to the press? "Only those deified fashion figures, usually the legendary head designer or creative director of a fashion brand, has the right to express their ideas, such as Karl Lagerfeld and Marc Jacobs.” In Cello’s experience, a brand's local team in Hong Kong was invariably an order-taker who might not necessarily know the original or authentic meanings of a new season's fashion collection and shop window designs. That revealed his discouraging the editorial staff from interviewing local brand representatives in hope of getting into the heart of a fashion brand and exploring the true meanings beneath various manifestations of fashion. “[T]hat would be fruitless” Cello asserted. When fashion publicists are asked to speak on behalf of their brands, no matter on what topic, many become very nervous and immediately turn it down. This caution is common to all the 
prominent brands. Even if they consider a media interview, their publicists will first ask what other brands have promised to contribute to the article. They will also enquire about their interviewer's position in the organization, the number of print pages involved, the questions to be asked and so forth, before promising to do the interview. They fear any unfavorable comparisons. Another factor is that fashion publicists rarely stay long with one brand or company. They would not take the risk of being criticized by their seniors for expressing their own preferences and views on fashion. Overall, a subconscious and internalized censorship system was observed among both the media gatekeepers and the fashion marketers.

However, the fashion publicists also take initiatives to maintain positive relationships with fashion editors. They send seasonal greeting cards and regularly deliver new product samples for trial. Fei Fei, Tina (a senior editor) and Kris regularly received expensive fashion products, cosmetics and skin care product samples from various brands. In Tina's case, she got too many of them each season and she herself could hardly use them all. It shows how fashion publicists strive to build rapport and influence fashion journalists to write good reviews of their products. Graphic designer Mag once said, "I feel that sometimes...the proposed editorial idea really depends on the relationship between the editors and fashion publicists...Maybe because the fashion editor personally doesn’t like a fashion brand or its publicist, not so relevant to its level 
of fashionability or its products, so he or she will not feature it... Or if you accept a particular brand's sponsorship to attend its catwalk show during the [Paris or Milan] Fashion Week, naturally you have to offer the brand editorial support.”

Fei Fei expanded on her role as a fashion editor. "I perceive myself as a messenger...My role is a messenger who is closer to the [fashion] creators... For example, I step into the backstage, witnessing how the facial makeup is done, greeting and talking to the supermodels too, but all don't really belong to part of the creation process. One can say that [fashion editors] are documenting things [from their] own perspective and disseminate the [fashion] messages to many more people. In my view, it's not a process of creation.”

\section{The Sales Team}

Fei Fei recounted how before she entered the fashion media industry she had already heard a lot of rumors about the perpetual battle between the writers and the salesmen in a magazine company. Her subsequent experience bore this out. Billy also admitted that he had encountered problems in cooperating with the editorial team in his daily work. "I'm not familiar with the situation in other fashion magazine companies...[The fashion journalists] don’t prefer handling these client-subsidized projects...they like to work on something initiated by themselves rather than the clients...this is a fundamental conflict...We are on many occasions not welcomed by 
the High Fashion journalists."

A comment from Billy summarizes the entire organization's nuanced negotiations with the fashion advertisers. "We lead the readers to perceive fashion from various perspectives. I believe this is what High Fashion has always been doing quite well, because many other magazines...they take the materials from the fashion brands and directly present them [to the readers]... almost in a 'straight-in-straight-out' mode....At High Fashion we digest the information provided, and then we'll do a brand new photography session... Of course the [promotional message] itself doesn’t change a bit, but at least we twist it a bit and adopt a new angle appropriate to the subject.”

\section{Conclusions: The Myths of Fashion}

\section{Commercial or Creative?}

The Critical perspective does seem to explain some of the characteristics of how media personnel present fashion in Hong Kong. They can be described as presenting a range of random, illogical notions of fashion as if they were normal. In various cases, an item's fashionability was observed to correlate primarily with its monetary value, the scale and financial status of the company behind it, and the amount of advertising dollars spent on it. Items not normally considered fashionable became fashionable in the right season. It seems that readers of fashion magazines can hardly escape from the 
matrix of deception constructed by the fashion media-a member of the mechanical culture industry that produces primarily standardized taste and style (Adorno and Horkheimer, 1986). Nonetheless, the pluralist postmodern perspective also helps illustrate important aesthetic, cultural, historical and social aspects of encoding fashion. In the global fashion media industry today, and certainly in Hong Kong, Jobling’s (1999) view of the power of iconic fashion seems sounder than Barthes’ (1990) theorizing about the power of fashion writing. The capitalist tone of the encoding process is unmistakable, but a participant observer must also acknowledge other creative possibilities as well as non-economic constraints in defining fashionability. Meanings are generated and adopted in pursuit of various goals — for the sake of art and aesthetic expression as Wilson (1985) suggests, but also for position-taking and to defend a cultural or ethical superiority as Bourdieu (1993) has asserted. Fashion meanings were encoded and decoded in a non-linear, complicated and diverse way.

\section{Preset or Negotiable?}

High Fashion aspires to encode authentic, exclusive meanings of luxury fashion.

In fact, though, fashion meanings were persistently being negotiated in and beyond the organization. Such internal and external negotiations reflected commercial logic, organizational structure and culture, but they also reflected the social and cultural myths which influenced the individuals involved. In High Fashion's case, on the one 
hand the chief editor wanted to maintain a consistent fashion aesthetic, and the staff worked together to sustain that vision. Yet their collaborations were partly in harmony and partly in tension, again due to their inconsistent understandings of fashion. They were constantly required to handle power politics within and beyond the organization. Apparently, they seemed to have a great deal of flexibility in selecting editorial topics and expressing individualistic and mix-and-match styles, but in the end their selections mostly followed the logic of commerce and highlighted potential advertisers’ brands.

Hong Kong journalists and designers appeared to have little creative control in encoding fashionability. At the same time, a consensual self-censorship scheme operated at High Fashion. Editorial and creative autonomy were limited and the advertisers' power in any negotiations were clearly observed. Overall, High Fashion's journalists felt that their editorial freedom was less than that of their counterparts at international fashion titles commonly regarded as shapers of global fashion trends. The disparate perceptions of creative autonomy in and beyond the organization reflected different images of fashion. They perceived the major Euro-American and Japanese fashion publications as the classics and disbelieved that their company had the same power in encoding fashion. By contrast journalists interviewed who were working in other fashion media organizations perceived the magazine as one of the local publications capable of at least partly twisting, partly adapting the Western notion of 
fashionability into its own "MILKX style”. This contradicts the idea of all-powerful fashion media and demonstrates the pluralistic, discursive and hybridized nature of fashion meanings Barnard has theorized (1996, 2007).

Even when the fashion media and the luxury and fashion companies explicitly show their commercial interest and orientation, that does not necessarily mean that fashion is essentially deceptive or uncreative. Neither does it confirm that the people involved in the encoding and decoding process are completely manipulated and being cheated.

Many of the fashion industry workers observed clearly understood the economically exploitative aspects of fashion industry in an unexpectedly clear way. Even so, they were not being manipulated nor ignorant of the literally generated fashion meanings in the encoding process. Rather, they made use of their understanding of and proximity to fashion creators (designers, stylists, photographers, etc.) as cultural capital to sustain what they regarded as their privileged, distinctive position in society (Bourdieu, 1993). They trust and mistrust fashion meanings simultaneously, and complex encoding and decoding proceed concurrently among them.

\section{Implications for further research}

This participant research aimed at discerning the encoding process of fashion in Hong Kong and mainland China, and included a three-month participant observation 
in the editorial team at High Fashion; in-depth interviews with 8 media personnel at High Fashion, 12 fashion journalists and bloggers from 12 different media organisations in Hong Kong and mainland China and marketing personnel from 16 global fashion conglomerates. However, according to the researcher's own reflection, the case of High Fashion and the interview responses from other 12 fashion journalists from other publications can only be regarded as a substantial yet specific case of fashion manifestation in Hong Kong context. To explore how other Asian fashion magazines autonomously or restrictively manifest fashion meanings, future researchers can consider conducting similar fieldwork in an international fashion media company in Hong Kong, mainland China, Korea or Japan for three months with similar work duties and research objectives. Comparative fashion ethnographies, in that case, can lead to further discussion and understanding of the complexity of encoding fashionability, cultural globalisation and glocalisation, and the advanced capitalist production and consumption patterns across greater China or even the Asia-Pacific region, in comparison with the Euro-American context.

Meanwhile, this research mainly focused on the production encoding stage of fashion in the Hong Kong and Asian media industry, one may wonder if fashion meanings are actually decoded and adopted in a conscious and meaningful way among mass fashion consumers in the reception stage. Whether the fashion consumers, in general, are as 
critical and knowledgeable as the fashion insiders when decoding the various facets of fashion representations, and how far do they actually make use such fashion meanings are not covered in this research, and they are indeed meaningful areas to be further investigated, say by questionnaire or focus-group interviews with a representable size of selected target segments, to find out how the encoding and decoding processes are manifested in readers and consumers, where the processes might be reversed to become decoding fashion magazines and encoding meanings through bodily expressions. The researcher anticipates that the contemporary readers and consumers will no longer passively decode the intended fashion meanings communicated by the fashion media, and within the dominant fashion discourse, they will still be able to improvise, reinterpret and negotiate fashion meanings with multiple agents in daily practices through their own habitus. The research on the decoding/reception stage of fashion will help the academics who are interested in the circulation of fashion meaning within the circuit of culture to comprehend its transformation from production, representation, identification and regulation to consumption in a more comprehensive way. Finally, the researcher believes that rather than the end of it, this is just the starting point of further investigation of fashion culture and communication in Asia.

This research provides insights and updated information for those whoare interested in the subject, to conduct research in a more informed and effective way in the future, for 
instance, the structure and culture of fashion media business as well as fashion

marketing practices in Asia, or a real case of how fashion meanings were actually and complexly negotiated in the fashion industry.

\section{References}

Adorno, T. W. (1975) ‘Culture industry reconsidered’. Trans. Rabinbach, A.G. New German Critique, 6: 12-19.

Adorno, T. W. and Horkheimer, M. (1986) Dialectics of enlightenment. Trans.

Cumming, J. London: Verso.

Barnard, M. (1996) Fashion as communication. London: Routledge.

Barnard, M. (2007) Fashion theory: A reader. London: Routledge. 
Barthes, R. (1990) The fashion system. Trans. Ward, M. and Howard, R. Berkeley: University of California Press.

Baudrillard, J. (1994) Simulacra and simulation. Trans. Glaser, S.F. Ann Arbor: University of Michigan Press.

Baudrillard, J. (2007) 'Fashion, or the enchanting spectacle of the code’. In: M. Barnard, ed. Fashion theory: A reader. London: Routledge, 462-474.

Bourdieu, P. (1993) Sociology in question. Trans. Nice, R. London: Sage.

Davis, F. (1992) Fashion, culture and identity. Chicago: University of Chicago Press.

Derrida, J. (1976) Of grammatology. Trans. Spivak, G.C. Baltimore: Johns Hopkins University Press.

DeWalt, K. M. and DeWalt, B. R. (2002) Participant observation: A guide for fieldworkers. Walnut Creek: AltaMira Press.

Entwistle, J. (2000) The fashioned body: Fashion, dress, and modern social theory. Cambridge, UK: Polity Press.

Evans, C. (2003) Fashion at the edge: Spectacle, modernity and deathliness. New Haven: Yale University Press.

Fiske, J. (1990) Introduction to communication studies. London: Routledge.

Hall, S. (2012) ‘Encoding/decoding’. In: M.G. Durham and D.M. Kellner, eds. Media and cultural studies: Keyworks. Malden: Wiley-Blackwell, 163-173. 
Hong Kong Population Census 2011 (http://www.census2011.gov.hk/en/index.html).

Jobling, P. (1999) Fashion spreads: Word and image in fashion photography since 1980.

Oxford: Berg.

Lehmann, U. (2000) Tigersprung: Fashion in modernity. Cambridge, Mass: MIT Press.

Ling, W. W. (2002) Deconstructing Hong Kong fashion system: Globalisation and cultural identity of fashion in Hong Kong. Unpublished PhD thesis, The Hong Kong Polytechnic University.

Lipovetsky, G. (1994) The empire of fashion: Dressing modern democracy. Princeton: Princeton University Press.

Lurie, A. (1981) The language of clothes. New York: Random House.

Marx, K. (1967) Capital, volume I. London: Dent.

Silverman, H. J. (1990) Postmodernism: Philosophy and the arts, New York: Routledge.

Skov, L. (2012) 'Hong Kong fashion designers as cultural intermediaries: Out of global garment production’. In. M. Barnard, ed. Fashion: Critical concepts in media and cultural studies volume III. Abingdon, Oxon; New York: Routledge, 326-342.

Simmel, G. (2004) 'The metropolis and mental life'. In: M. Miles and T. Hall, eds. The city cultures reader. London: Routledge, 12-19. 
Svendsen, L. (2006) Fashion: A philosophy. Trans. Irons, J. London: Reaktion.

Thomas, D. (2007) Deluxe: How luxury lost its luster. New York: Penguin Press.

Veblen, T. (2012) 'Dress as an expression of the pecuniary culture’. In: M. Barnard, ed.

Fashion: Critical concepts in media and cultural studies volume III. Abingdon, Oxon; New York: Routledge, 117-125.

Weiss, A. S. (1990) ‘Lucid intervals: Postmodernism and photography’. In: H.J. Silverman, ed. Postmodernism: Philosophy and the arts. New York: Routledge, $155-172$.

Wilson, E. (1985) Adorned in dreams: Fashion and modernity. London: Virago.

\section{Figures:}




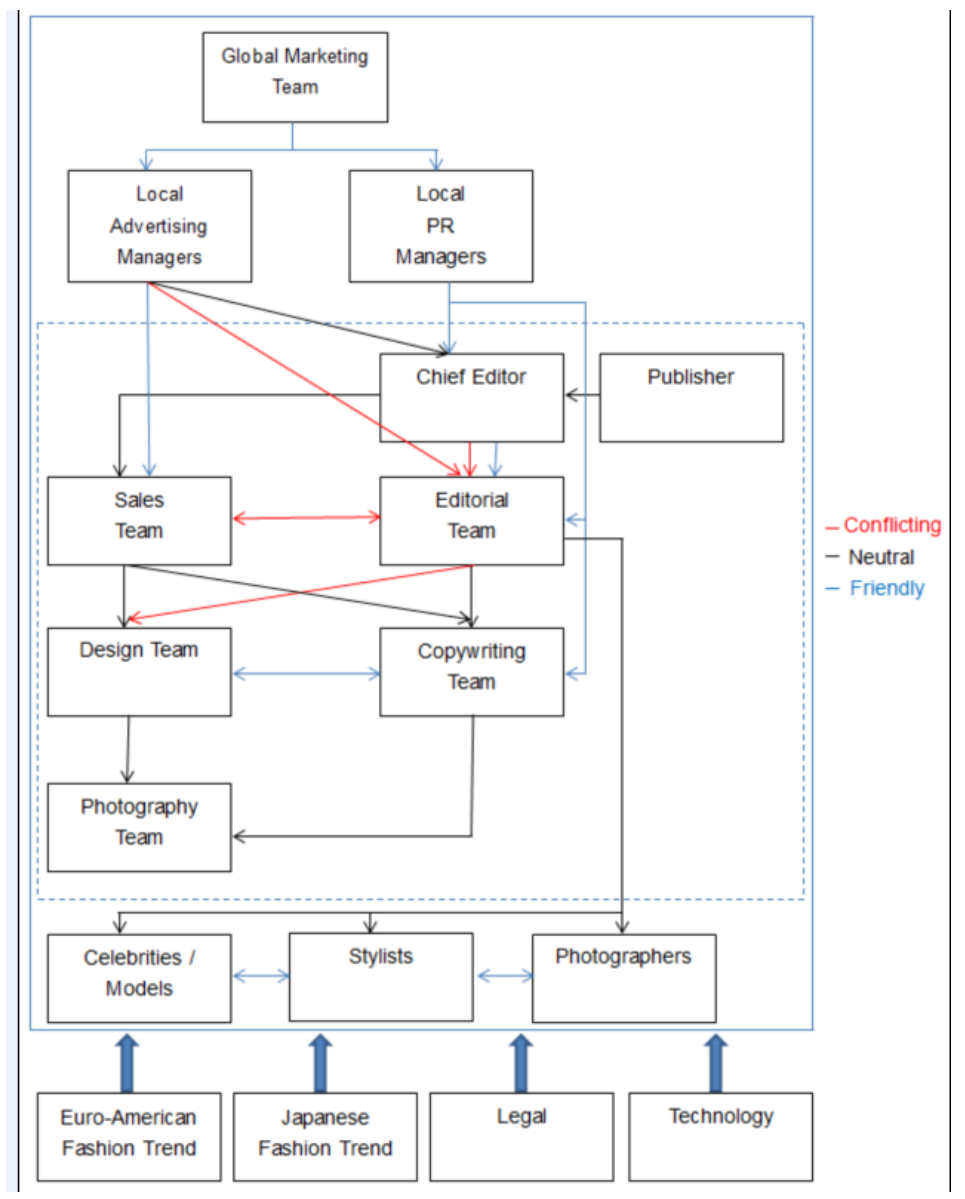

Figure 1. Negotiations in and beyond High Fashion.

\section{Appendixes:}

Appendix 1: Samples of the Coding Chart for the Thematic Classifications

1. Asian fashion media personnel (Personal Level):

1.1 Conception of fashion

1.1.1 Written (textual)

1.1.2 Iconic (graphical/visual)

1.1.3 Physical/tangible

1.1.4 Psychological/intangible

1.1.5 Affiliation (with specific firm, institution, etc.) 
1.1.6 Any other association (with specific people, culture, nation, history, class, etc.)

1.2 Conception of non-fashion

1.2.1 Written (textual)

1.2.2 Iconic (graphical/visual)

1.2.3 Physical/tangible

1.2.4 Psychological/intangible

1.2.5 Affiliations (with specific firm, institution, etc.)

1.2.6 Any other associations (with specific people, culture, nation, history, class, etc.)

1.3 Personal qualities

1.3.1 Interest in fashion

1.3.2 Knowledge of fashion

1.3.3 Experience \& qualifications

1.3.4 Appearance, lifestyle and social network

\subsubsection{Others}

1.4 Self-perception at work

1.5 General insights about the fashion industry

1.6 Career aspirations

3. High Fashion (Organizational Level - Case study)

3.1 Now and then

3.2 Organization structure and hierarchy

3.3 Organizational culture and socialization

3.4 Work mode

3.4.1 Work time 
3.4.2 Work space

3.4.3 Work nature

3.4.3.1 Copywriting/project team

3.4.3.1.1 Main book

3.4.3.1.2 Special creative

3.4.3.1.3 Other projects

3.4.3.2 Design team

3.4.3.2.1 Print

3.4.3.2.2 Online

3.4.3.3 Editorial team

3.4.3.4 Photography team

3.4.3.4.1 In-house photographers

3.4.3.4.2 Outside photographers

3.4.3.5 Sales team

3.4.4 Work prospects/promotion path

3.5 Production

3.5.1 Typical procedures

3.5.1.1 Producing the textual content

3.5.1.1.1 Research and preparation

3.5.1.1.2 Topic meeting \& discussion

3.5.1.1.3 Execution

3.5.1.1.4 Revision

3.5.1.2 Producing the graphic content

3.5.1.2.1 Research and preparation

3.5.1.2.2 Topic meeting \& discussion

3.5.1.2.3 Execution 
3.5.1.2.3.1 Celebrity/model photography

3.5.1.2.3.2 Product photography

\subsection{Revision}

3.5.2 Collaboration/clash with internal parties

3.5.3 Collaboration/clash with external parties

3.5.4 Level of creativity

3.6 Resources 


\section{Contributor details}

Tommy Tse is Assistant Professor at the Department of Sociology, The University of Hong Kong (HKU). He completed his Bachelor's and M.Phil. degrees at the Department of Comparative Literature, HKU, with his expertise in gender studies and literary and cultural theories, and his Ph.D. at the Department of Sociology, HKU, specializing in the interdisciplinary study of fashion communication, media and cultural industries in the Asian context. His works have appeared in Asian Journal of Business Research (MAGScholar), International Journal of Fashion Design, Technology and Education (Taylor \& Francis), International Journal of Fashion Studies (Intellect), Clothing Cultures (Intellect) and Luxury Brands in Emerging Markets (Macmillan). Tse has acquired experience and knowledge in marketing and advertising in various media companies and creative service agencies, including ADO and TBWA. Before joining HKU, Tse worked at the School of Communication, Hong Kong Baptist University, the Department of Fashion and Image Design, Hong Kong Design Institute (HKDI), and the Culture and Media Domain, HKU SPACE CC.

\section{Contact:}

Room 9.09, The Jockey Club Tower, Department of Sociology, The University of Hong Kong, Pokfulam, Hong Kong.

E-mail: tommyt@hku.hk 